\title{
A Review in Fault Diagnosis and Health Assessment for Railway Traction Drives
}

\author{
Fernando Garramiola * ${ }^{\mathbb{D}}$, Javier Poza, Patxi Madina, Jon del Olmo and Gaizka Almandoz \\ Faculty of Engineering, Mondragon Unibertsitatea, 20500 Arrasate-Mondragón, Spain; \\ jpoza@mondragon.edu (J.P.); pmadina@mondragon.edu (P.M.); jdelolmo@mondragon.edu (J.d.O.); \\ galmandoz@mondragon.edu (G.A.) \\ * Correspondence: fgarramiola@mondragon.edu; Tel.: +34-943-794-700
}

Received: 16 November 2018; Accepted: 29 November 2018; Published: 3 December 2018

\begin{abstract}
During the last decade, due to the increasing importance of reliability and availability, railway industry is making greater use of fault diagnosis approaches for early fault detection, as well as Condition-based maintenance frameworks. Due to the influence of traction drive in the railway system availability, several research works have been focused on Fault Diagnosis for Railway traction drives. Fault diagnosis approaches have been applied to electric machines, sensors and power electronics. Furthermore, Condition-based maintenance framework seems to reduce corrective and Time-based maintenance works in Railway Systems. However, there is not any publication that summarizes all the research works carried out in Fault diagnosis and Condition-based Maintenance frameworks for Railway Traction Drives. Thus, this review presents the development of Health Assessment and Fault Diagnosis in Railway Traction Drives during the last decade.
\end{abstract}

Keywords: Fault Diagnosis; Health-Assessment; Condition-based maintenance; railway traction drives

\section{Introduction}

In the last decade, due to the increasing importance of availability in Railway systems, early fault diagnosis and Condition-based maintenance (CBM) have become key points for Railway industry. CBM is based on system health monitoring for decision-making [1]. An easy way to formalize a CBM framework is using the standard ISO 13374 [2], in which the CBM tasks are divided into six different levels. The ideal maintenance strategy should be able to act once a fault is detected and before the failure occurs. Thus, cost-effectiveness maintenance decision is made without worsening the availability of the system. Maintenance decision-making can be done based on diagnosis or prognosis. Diagnosis aims to detect and isolate faults, whereas prognosis estimates the future state of a component. Furthermore, other solutions have arisen, as Prognosis and Health Management (PHM), in order to predict and protect the systems based on estimation of time to failure [3]. A review of prognosis methods is presented in [4], classifying the methods depending on the computational resources and historical data quantity needed.

CBM requires fault diagnosis for Health Assessment (HA). Fault Detection and Isolation (FDI) approaches detect and located the fault, whereas Fault Detection and Diagnosis (FDD) approaches provide the fault severity too. In case of complex systems and multivariate analysis, FDI approaches can be mainly classified as Model-based and Data-driven. A comparison of different Data-driven approaches, such as Principal Component Analysis (PCA) and Partial Least Squares (PLS), is given in [5]. Model-based approaches require a physical knowledge of system, whereas data-driven approaches need a large quantity of data. Model-based approaches require the development of an analytical model, that simulates the system behaviour, in order to calculate the difference between the real system and the analytical model output, this difference is called residual. This is the signal used 
for fault detection, as it is shown in Figure 1. Analytical models are mainly developed by structural approaches [6], based on consistency relation and observer-based approaches [7]. Residual evaluation is done using norms or statistical methods [8]. Some statistical methods are Hypothesis tests or Likelihood ratio (LR). Likelihood ratio is given by Equation (1), being $p$ the probability density for a normal distribution $\mathrm{N}\left(\mu, \sigma^{2}\right)$, where $\mu$ is the mean value and $\sigma^{2}$ is the variance. Probability density is given by Equation (2) to evaluate the residual $r$. Thus, $p(r)$ gives the probability of a given sample of the residual to be within the normal distribution $\mathrm{N}\left(\mu, \sigma^{2}\right)$. On the other hand, LR shows which of the compared probability densities is more probable. For example, if a faulty case given by $p_{1}$ is compared to a fault-free case given by $p_{0}$, as it is shown in Equation (1), in case that the $L R(r)>0$ faulty case is accepted, as $p_{1}$ is more probable than $p_{0}$, otherwise it is a fault-free case.

$$
L R(r)=\ln \frac{p_{1}(r)}{p_{0}(r)}
$$

being $p_{1}$ and $p_{0}$ the probability density of the residual for two normal distributions, for example, faulty and a fault-free cases.

$$
p(r)=\frac{1}{\sigma \sqrt{2 \pi}} e^{-\frac{(r-\mu)^{2}}{2 \sigma^{2}}},
$$

being $\mu$ and $\sigma^{2}$ the mean value and variance of the normal distribution to which the residual will be compared.

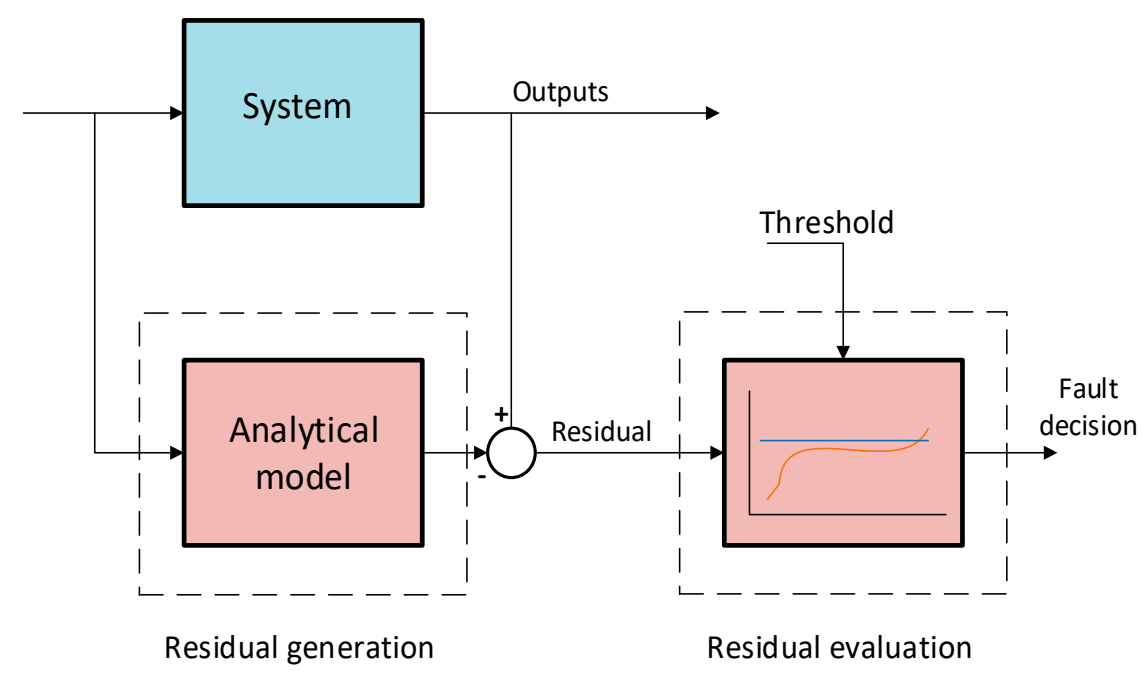

Figure 1. Model-based fault diagnosis.

On the other hand, in data-driven approaches, it is assumed that a fault alters some of the measured signals, so features for fault detection are obtained from those signals, using mainly signal processing or statistics. In case of data-driven approaches, a fault-free training is required in order to get a pattern. In case that fault detection can be done by analysis of just one signal, signal-based approaches can be used. In contrast to other Data-driven approaches, Signal-based approaches are based on signal processing and they do not need a previous training. Fusion of different FDI approaches are presented in [9]. Fusion can benefit from advantages of different FDI approaches. A review of different FDI approaches is presented in [10]. Based on [11], a classification of main FDI approaches is shown in Figure 2, although there are other techniques, such as artificial intelligence based [12], bond graph [13] or hybrid approaches [4], which are not presented. Diagnostic observers for model-based approaches, PCA for data-driven and Motor current signature analysis (MCSA) for signal-based are some of the most usual FDI approaches in electric drives. 


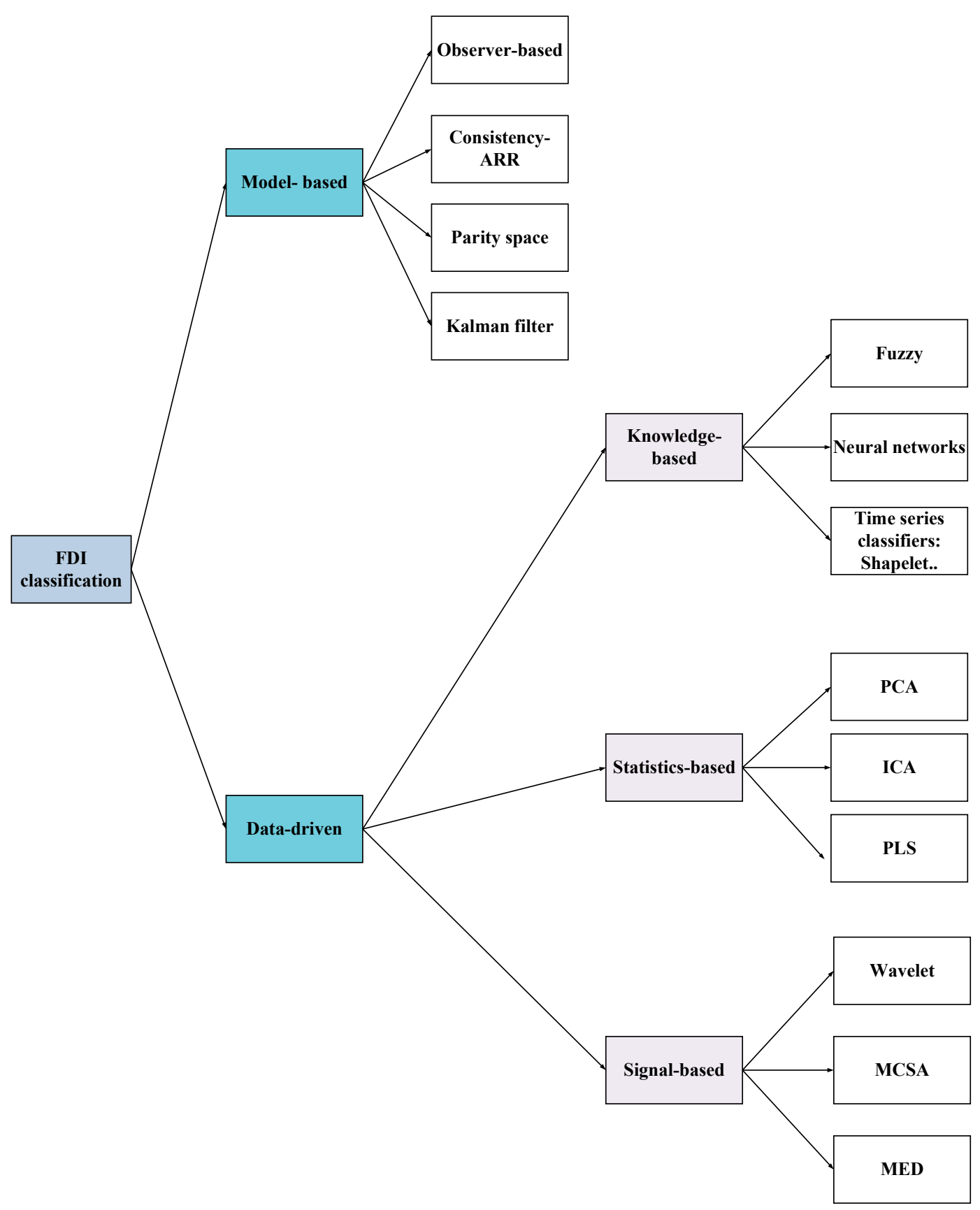

Figure 2. Fault detection and isolation (FDI) approaches classification.

Furthermore, there are review articles related to fault diagnosis in renewable energies applications [14,15] and aerospace applications [16], as well as a review in Railway applications but focused on the wheel-rail and suspension health monitoring [17].

In Railway systems, historically corrective maintenance and planned preventive maintenance have been applied. Recently, due to the improvement of technology and computational capabilities, frameworks for HA and CBM have been applied to Railway systems [17-20].

Among the different parts in railway systems, traction drives play an important role, as they are responsible for train motion. The main faults in traction drives occur in sensors, power electronics devices and electric motors. In [21] the sensor technology in railway traction drives is presented. In case of faults, incipient or abrupt, the system performance is degraded and early fault diagnosis should be implemented in order to prevent a failure and improve the availability. On the other hand, 
in case of hard faults, mainly in sensors that take part in the control strategy, the system leaves the safety zone and protections act. Thus, it could be hard to avoid the failure and there could be a loss of availability, unless a fault tolerant control (FTC) is implemented. A review of FTC is presented in [22]. Several publications related to the application of FDI to electric traction drives are presented in the literature [23]. The research works are focused on sensors [24-26], power electronics devices [15,27] and electric motors [28-30].

Furthermore, although during the last decade several publications related to fault diagnosis and health assessment in Railway traction drives have been published [25,31-33], there is not a review, which summarizes all the research work done in Railway traction drives. Previous review works are focused on sensors more than in fault diagnosis [21] or on fault diagnosis in railway traction power supply [18].

The objective of this article is to present the latest research works in fault diagnosis and health assessment in Railway traction drives, as an essential asset for its integration in a CBM system. Scopus and Web of Science databases have been used, following PRISMA guidelines, in order to gather the relevant research works. First, documents are selected in case of finding one of the following keywords: "fault," "monitoring" or "maintenance" on the author keywords, abstract or title. In addition to these keywords, search was limited to documents where "railway" and "traction" keywords appear on the title. Then, the search was refined to articles and conference proceedings since 2005, in the field of engineering, computing and decision sciences. 80 documents in Scopus and 62 in Web of Science were listed and both lists were compared to avoid duplicities. Finally, the documents were analysed in order to select the ones related to health assessment and fault diagnosis in Railway Traction drives.

The article has the following structure: Section 2 summarizes the research works in Health assessment and CBM in Railway traction drives. Section 3 presents different FDI approaches applied to Railway systems. Section 4 presents the state of the art of fault diagnosis in Railway Traction Drives. Finally the discussions and conclusions are given.

\section{Condition-Based Maintenance in Railway Systems}

In opposition to run-to failure or corrective maintenance, in which the goal is to replace the faulty component, preventive maintenance strategies, aims to prevent the failure, by means of condition monitoring and early fault detection. A classification of maintenance strategies is presented in Figure 3.

Several reviews in CBM are available in the literature [1,34-37] A comparison between CBM and Time-based maintenance (TBM) is presented in [38]. The cost-effectiveness of CBM is dependent on some factors, such as condition monitoring quality and required planning time.

In [39] a framework for CBM implementation is presented. The framework is based on five different blocks in order to improve the interaction among the different disciplines during CBM design and implementation periods. The framework integrates tools as Failure mode and Effects Analysis (FMEA) and standards as ISO 13374. Standard ISO13374, developed for condition monitoring and diagnostic of machines, presents the following functional modules for CBM implementation: Data Acquisition (DA), Data Manipulation (DM), State Detection (SD), Health Assessment (HA), Prognostics Assessment (PA) and Advisory Generation (AG). An example of each module functionality is shown in Figure 4. In the example presented, in the HA module, not only the diagnosed faults are given, the effects on system performance are presented too, in order to help in the maintenance decision-making [40].

In [41], the application of the standard ISO 13374 to a railway system is proposed. An on-board diagnosis is proposed, being the DA, DM, SD and HA on-board implemented, whereas in a remote diagnosis only DA, DM and SD are on-board implemented and data is sent to maintenance centre for diagnosis, as it is shown in Figure 5. Furthermore, in Figure 6, a distributed supervision is presented, in opposition to centralized supervision where a global diagnosis is done. Thus, in the distributed supervision there are local diagnosis units apart from a global one. 


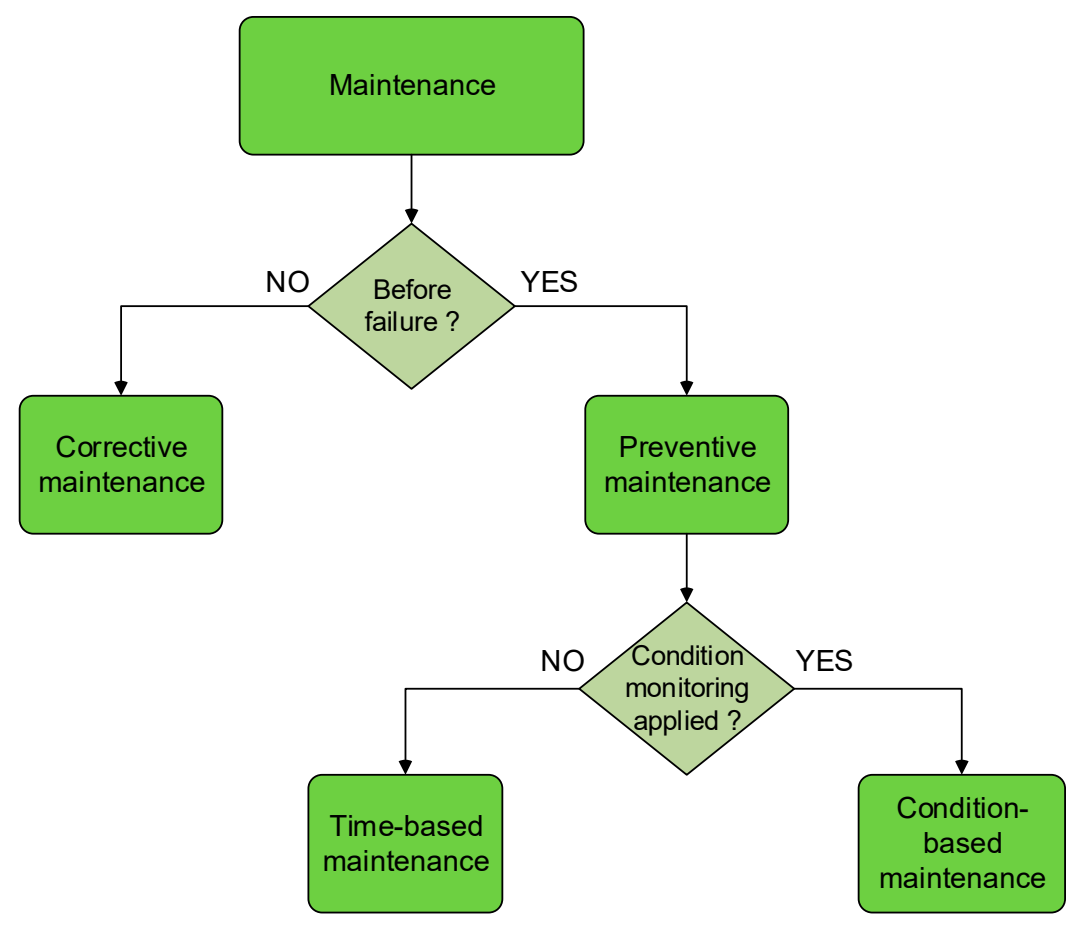

Figure 3. Classification of maintenance strategies.

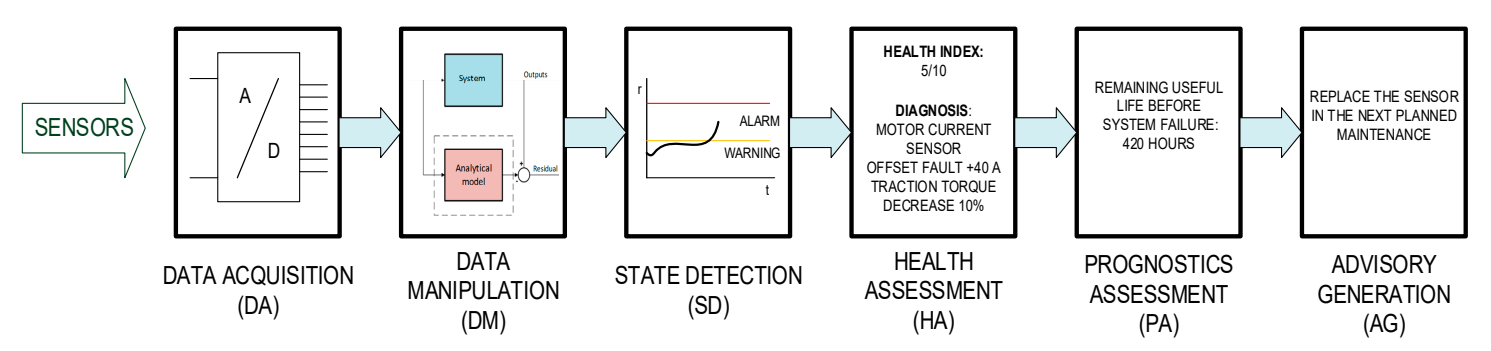

Figure 4. Functional modules of ISO 13374 based on [2].

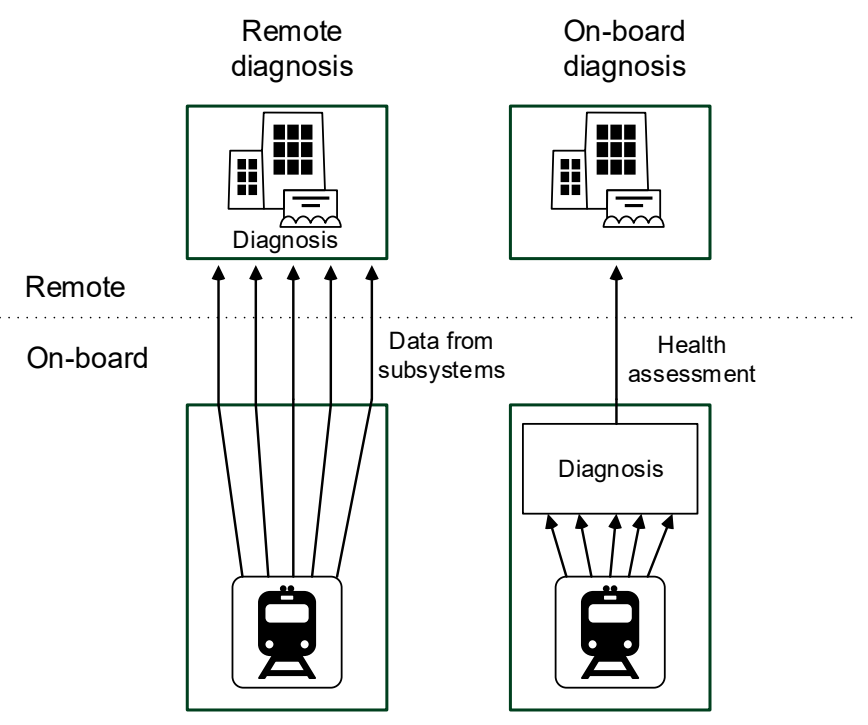

Figure 5. Remote and on-board diagnosis.

On-board equipment is normally limited in data storage capacity. On-board diagnosis allow providing HA and there is no need to store so many variables, just the fault indicators. Moreover, communication from train to remote supervision is bounded by transceivers availability and 
communication latency. In the near future, this latency could be lower than $100 \mathrm{~ms}$ [42]. Thus, on-board diagnosis is more suitable when real-time FDI methods should be implemented, whereas remote diagnosis can be used for delayed HA, as the data are offline analysed. Data can be sent to remote diagnosis, with a time interval over the aforementioned latency, or at the end of the day, depending on the celerity of the maintenance decision-making to offer.

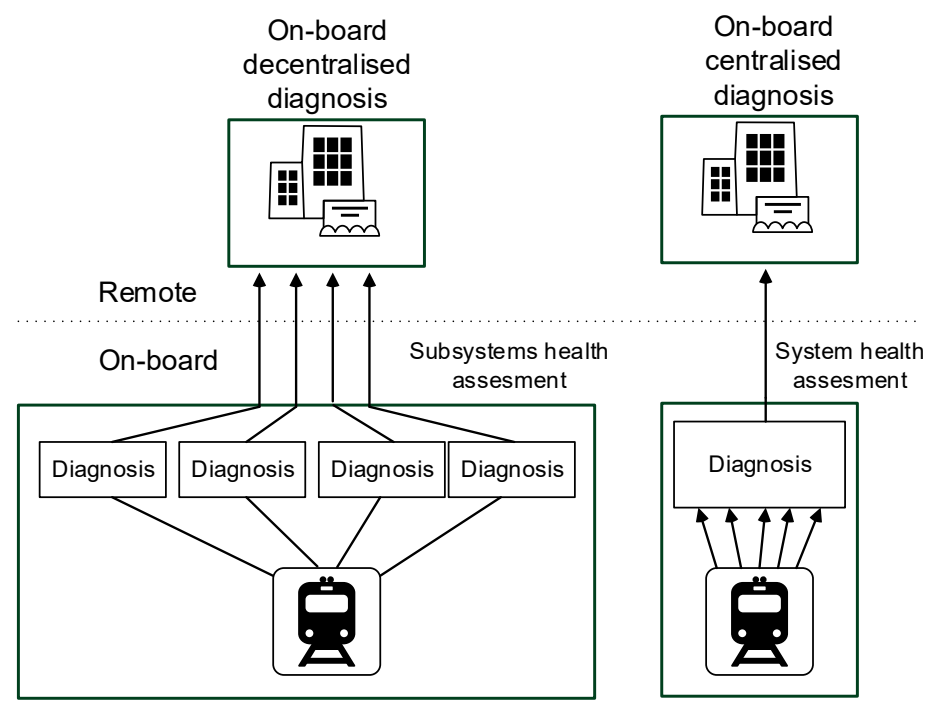

Figure 6. Decentralised and centralised diagnosis.

In [43] a proposal of CBM for on-board equipment application in a railway application is presented. A rating criterion for health status is presented, as well as four different levels for health assessment.

A transition from preventive to predictive maintenance for railway systems is presented in [44], presenting a solution based on remote diagnosis and prognosis. This transition is one of the key points for the smart maintenance proposal in [45]. Other key points in smart maintenance are asset management, support system by artificial intelligence and integrated database. The asset management aims to plan an optimal maintenance in systems, which deterioration is slow but maintenance work takes long. Support system by artificial intelligence expects to help maintenance engineers in the decision-making. Nowadays, engineers need a long-term expertise in order to be able to take a maintenance decision. Finally, an integrated database is needed in order to have all the data coming from maintenance and diagnosis tools available, as well as the historic data.

There are different commercial supervision systems in order to improve the maintenance service, as it is shown in Table 1, mainly based on data monitoring and communication to remote supervision. Moreover, Shift2rail [46] is a public-private initiative, where European Union and main rail equipment manufactures promote innovations in railway, being the smart maintenance a key point.

Table 1. Commercial supervision systems.

\begin{tabular}{cc}
\hline Company & Supervision System \\
\hline CAF & sDiag, COSMOS \\
Bombardier & ORBIFLO, AIMS \\
Siemens & Railigent \\
Alstom & TrainTracer, HealthHub \\
\hline
\end{tabular}

On the other hand, there is a need to improve the synergy between maintenance and safety engineering teams. In Railway applications, safety engineers should develop a FMEA in order to elaborate a safety analysis. A safety analysis is needed in order to identify the most critical components in the system. Unfortunately, the information available in the FMEA is mainly qualitative, providing 
just risk priority numbers (RPN) to quantify the effects on the system, being limited for maintenance use. Thus, some research works use fault injection techniques and Hardware-in-the-loop (HIL) validation to quantify the effects. In [40] the fault injection technique is used for system analysis under sensor faults. The analysis results have been used to enhance the initial FMEA, already available from safety engineers, as well as its integration in design, validation and maintenance tasks, as it is shown in Figure 7. FMEA is enhanced with field information obtained from maintenance engineers and with system analysis under faults in the HIL platform. A fault injection technique has been used in several other railway applications [47-49], validating the analysis in simulation or in HIL platforms, composed of a Real-time simulator and a commercial TCU.

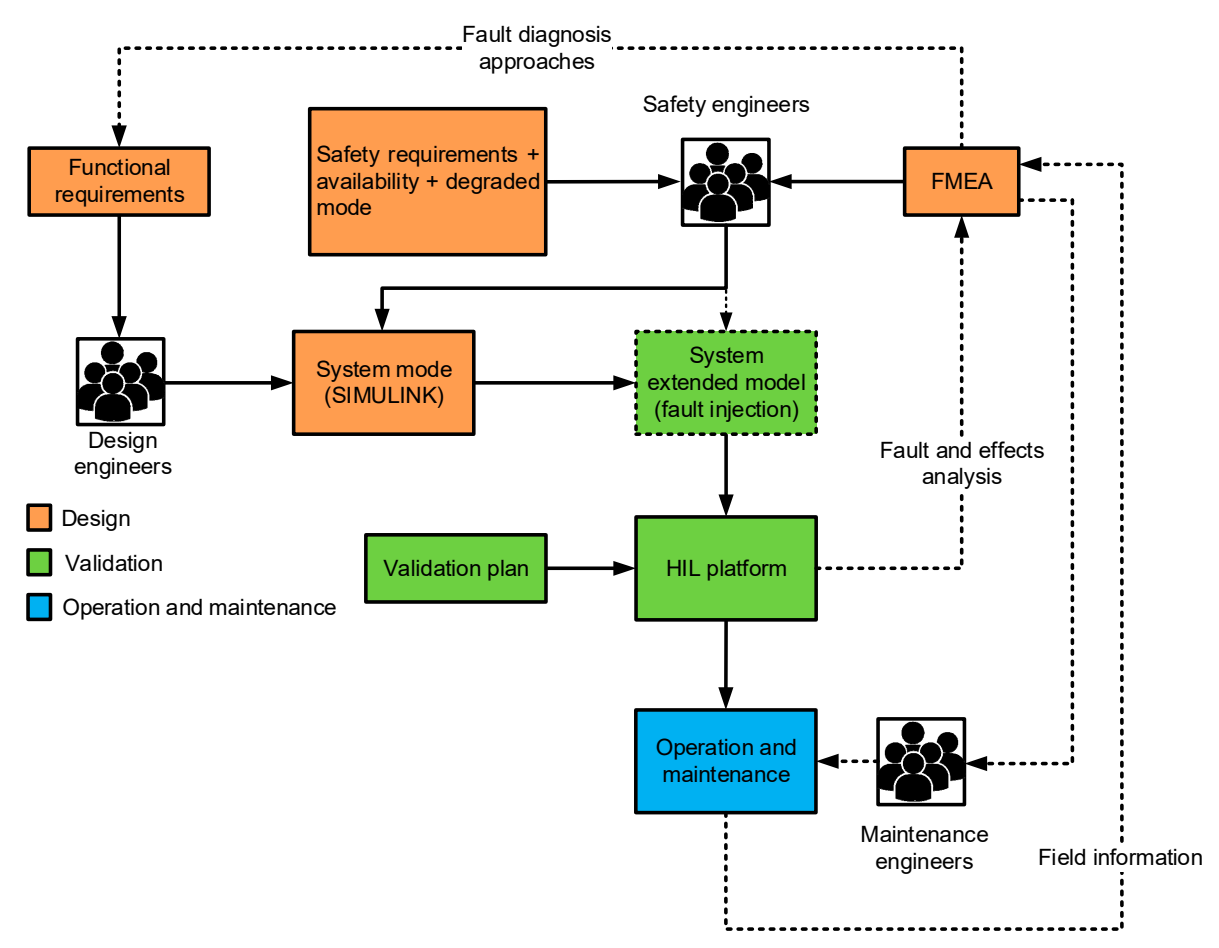

Figure 7. Integration of failure mode and effects analysis (FMEA) and fault injection for maintenance [48].

The influence on maintenance of Internet of Things (IoT) and new communications technologies is reviewed in [50]. IoT can help in the implementation of a preventive maintenance and a dynamic decision-making in railway systems due to the information obtained from collected data.

In [51] a review in PHM is presented. A case study on a bogie is presented too. The authors propose four steps for PHM implementation: component critical analysis, sensor selection for condition monitoring, data processing and prognostics approach. The component critical analysis can be done by means of the aforementioned FMEA. Sensor selection is essential to represent system degradation. Furthermore, the cost of sensors should be considered for the cost-effectiveness of condition monitoring system. The prognostics approach proposed is hybrid, based on the combination of model-based and data-driven approaches. A comparison among different approaches for prognosis is presented.

\section{Fault Diagnosis in Railway Systems}

A variety of fault diagnosis approaches has been used for electric and mechanical parts in Railway Systems. Apart from Railway Traction drives, which will be reviewed in the following section, previously mentioned FDI approaches have been applied to other parts of Railway Systems. In [52,53], a vision-based condition monitoring is applied in order to detect faults in railway lines. An online-monitoring is proposed in [54] for rail fasteners, analysing acceleration signals with wavelet transform. Wavelet transform [55] allows analysing a signal by mean of a variable time 
window and different scaling, inversely proportional to frequency, as it is shown in (3) for continuous wavelet transform.

$$
w t(s, \tau)=\frac{1}{\sqrt{s}} \int_{-\infty}^{\infty} x(t) \Psi^{*}\left(\frac{t-\tau}{s}\right) d t,
$$

being $\Psi^{*}\left(\frac{t-\tau}{s}\right)$ the complex conjugate of wavelet basis for the time translation $\tau$ and scaling $s$ and $x(t)$ the signal to transform.

One of the applications of wavelet transform is the suppression of the noise in the original signal. Based on wavelet transform, Wavelet Packet Transform (WPT) improves the resolution for high-frequency region. The signal is decomposed into approximation and detail signals, then the detail signals are limited to a threshold and finally the signal is reconstructed based on approximation and detail signals. In case of fault detection applications, a suitable wavelet basis should be chose in order to classify between fault-free and faulty cases. Wavelet basis could be selected to identify changes in entropy, energy and so forth. In [56] WPT energy is applied to vibrations signals in combination with neural networks, in order to detect faults in the axle of bogies.

Vibration signals are analysed by mean of another signal-based approach, an improved Minimum Entropy Deconvolution (MED) [57], in order to detect faults in bearing. The method presented improves the fault diagnosis in case of low signal-to-noise ratio compared to classical MED.

On the other hand, among the statistics-based approaches, in [58] Principal component analysis (PCA) is used for railway line fault detection. PCA [59] is multivariate statistical method, where the data, normally normalized and based on a large quantity of observations and variables, are representing in a new space, with a lower dimension than the original one and given by principal vectors. PCA decomposes the data into two matrices, one including the score vectors, which represent the data in the new space and another one for the loading or principal vectors. A variety of decomposition algorithms are used to obtain the principal components, in order to improve the detectability of variations in the data, setting the component with major changes in horizontal axis and the second one with major changes in vertical axis, as it is shown in the example, based on motor phase currents, in Figure 8. PCA approach needs historical fault-free data for fault detection. First, an offline step based on fault-free data, in order to obtain the fault detection threshold, then an online step to compare the actual data to the threshold for fault detection. Among others, Hotelling's $\mathrm{T}^{2}$ and squared prediction error (SPE) statistics tests are used for threshold setting and fault detection. A variation of PCA is applied in [60] in order to detect faults in transformers, being more adequate when data have complex non-linear relationship. In [20] the data for railway point machine (RPM) replacement is obtained based on electric current monitoring and Shapelet method. Training data is required for its application too.

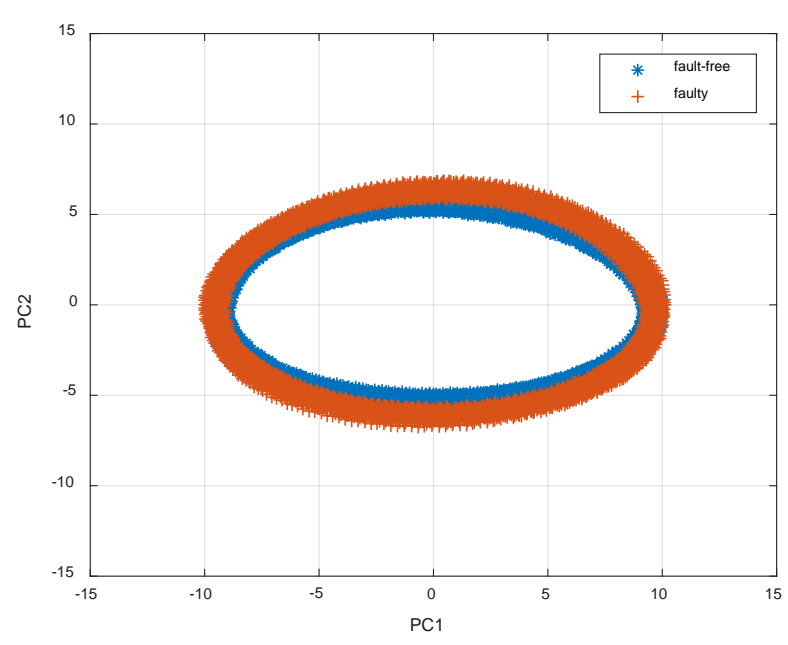

Figure 8. Scores of principal component analysis (PCA) application for an unbalance in an induction motor phases for an operation point. 
Among the model-based approaches, a consistency-based approach, given analytical redundancy relations (ARR), is proposed for traction power supply fault detection [61]. An Observer-based approach is presented in [62] for sensor fault detection in the suspension system. A hypothesis test is utilized for residual evaluation.

\section{Fault Diagnosis in Railway Traction Drives}

The railway traction drive is a key point for the Railway system availability. Railway traction drives are fed with DC supply provided by an external substation, as it is shown in Figure 9, or with AC supply, including a transformer and a rectifier onboard, as it is shown in Figure 10. In both cases, the main parts of a Railway Traction drive are the electric machine, the power electronics, the traction control unit (TCU) and the sensors. Although there are railway traction drives based on other technologies, such as DC motors and thyristors, nowadays, the most usual configuration is based on induction motors (IM) and Insulated Gate Bipolar Transistors (IGBT). Thus, this configuration will be proposed as example in this article.

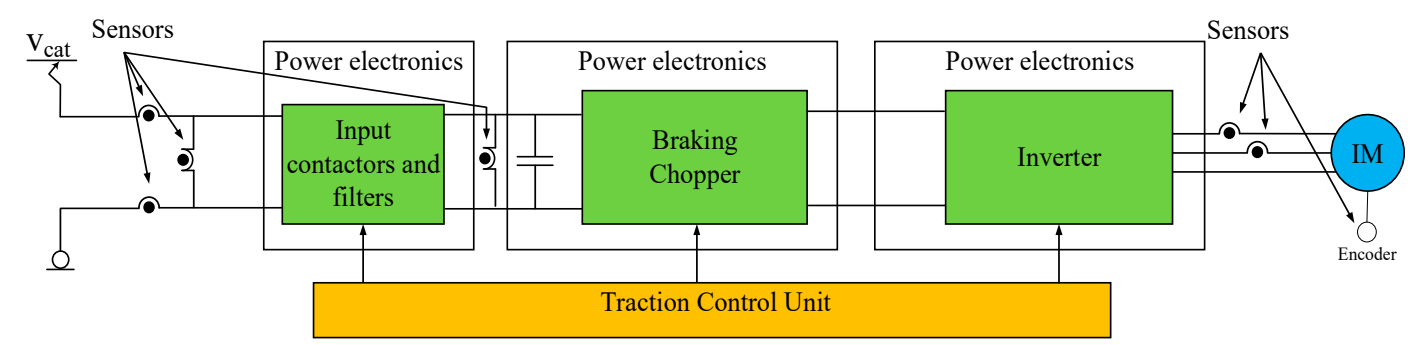

Figure 9. Structure of a Railway traction drive connected to DC catenary.

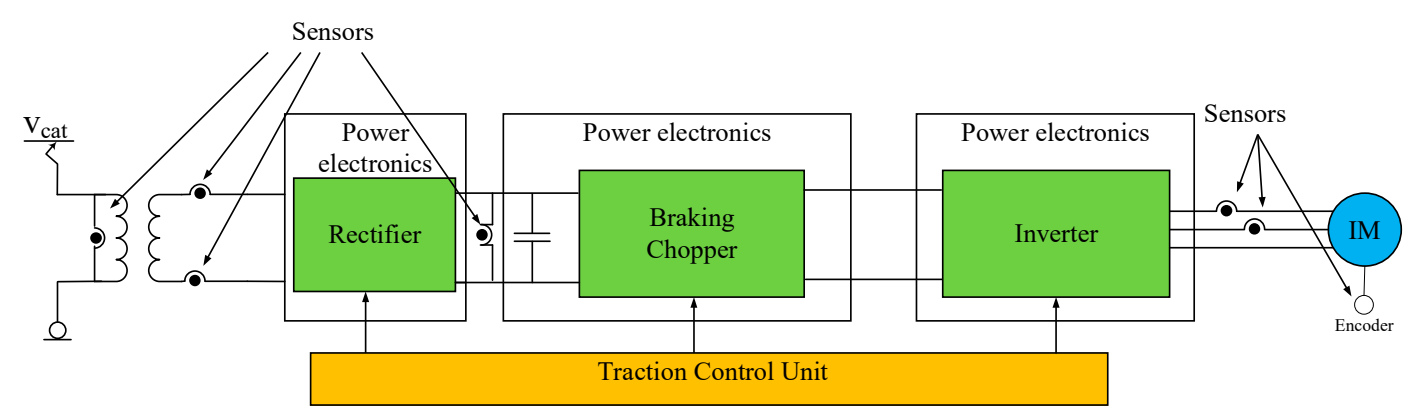

Figure 10. Structure of a Railway traction drive connected to AC catenary.

In power electronics, power converters, power switches and passive components, as the DC-link capacitor, are included. The power converters in a DC catenary supplied Railway traction drive are an inverter to supply the motor and a braking chopper, whereas a rectifier is needed to be added, in case of AC catenary supply. The inverter transfers power in DC-link to the electric machine, normally an induction motor, during traction or returns to DC-link from motor during braking operation. Furthermore, by means of a chopper, energy is dissipated in the braking resistor in case that the energy cannot be returned to catenary. In case of AC catenary, a controlled rectifier for AC/DC conversion is used.

The electric machine is connected to a gearbox, which is connected to the bogie axle to move the train [19]. One inverter can supply one or more electric motors in parallel.

The TCU is the responsible for the execution of the switching modulation for power converters, as well as main and pre-charge contactors and protections management. Sensors measurements are monitored by the TCU for control strategy and fault diagnosis algorithms.

From 2005, several research works related to fault diagnosis in Railway traction drives have been published. In this review, fault diagnosis research works have been classified in three groups, as a 
function of the item where the approach is applied. Thus, these three groups are electric machines, sensors and power electronics separately.

Although there are interesting articles and reviews in fault diagnosis for traction drives $[28,30]$, the applications works for Railway traction drives are more limited. Thus, in the following subsections, the fault diagnosis research in Railway traction drives is presented, analysing the fault diagnosis in electric machines, sensors and power electronics. Furthermore, the fault diagnosis approaches implemented in Railway traction drives are summarized in Table 2.

Table 2. FDI approaches in Railway Traction drives.

\begin{tabular}{|c|c|c|c|c|}
\hline FDI Approach & Reference & Electric Machine & Sensors & Power Electronics \\
\hline MCSA & [63] & Rotor bars & & \\
\hline VCT & [64] & Rotor bars & & \\
\hline Flux FFT & [65] & Dirt & & \\
\hline Current transient FFT & [66] & Insulation degradation & & \\
\hline Observer-based & {$[31,33,67-71]$} & & Voltage and current & \\
\hline ToMFIR & {$[72,73]$} & & Speed and current & \\
\hline PCA, ICA & {$[74,75]$} & & Voltage, current and speed & \\
\hline Model-based estimator & {$[32,76]$} & & & Power switches \\
\hline Wavelet entropy & [77] & & & Power switches \\
\hline Wavelet energy and SVM & [78] & & & Power switches \\
\hline Current FFT & [79] & & & Power switches \\
\hline Fault signatures analysis & [80] & & & Power switches \\
\hline Least squares & [81] & & & Capacitor \\
\hline
\end{tabular}

\subsection{Fault Diagnosis in Electric Machines}

Induction motors are the most usual electric machines in railway applications, although recently permanent magnet motors have been utilized too for railway applications [82]. The main faults in induction motors are rotor faults, stator windings faults and mechanical faults [30]. The rotor faults are mainly due to broken rotor bars or core damage. Stator winding faults are given by inter-turn short-circuits. On the other hand, there is a variety of mechanical faults, such as eccentricity and bearing faults. Bearing faults are the most usual faults in electric machines according to [83].

Despite the variety of fault diagnosis approaches for induction machines presented in the literature [84-87], the application to Railway traction drives is more limited. Thus, in [63] the rotor bars faults are detected by Motor current signature analysis (MCSA) for an induction motor used for a high speed railway application. MCSA is one of the most usual signal-based FDI approach for fault detection in electric machines. MCSA is based on stator current frequency spectrum analysis for faulty induction machine in comparison to a fault-free induction machine and its main drawback is that it can be only applied in steady state. An example for an induction motor with unbalanced phases is shown in Figure 11. Faults such as rotor bars breakage, eccentricity or inter-turn short-circuits can be detected [30] with this strategy. On the other hand, in [64] the oscillation that arises in the flux when a rotor fault occurs is analysed. The oscillation frequency is twice the slip frequency. This approach, called Virtual Current Technique (VCT), can be used in transient and steady states. Furthermore, compared to other techniques as Vienna Monitoring Method (VMM), VCT allows linking the oscillation and the number of broken rotor bars. FFT is used too in [65] to detect dirt in motors, as the accumulation of electromagnetic material generates changes in the flux harmonics amplitudes. Finally, in [66] the motor winding insulation degradation is detected. Inverter applies a step voltage to each motor phase and transient current are analysed. An insulation degradation is revealed in a parasitic capacitor change, being the capacitor the main factor for the current transient behaviour. 


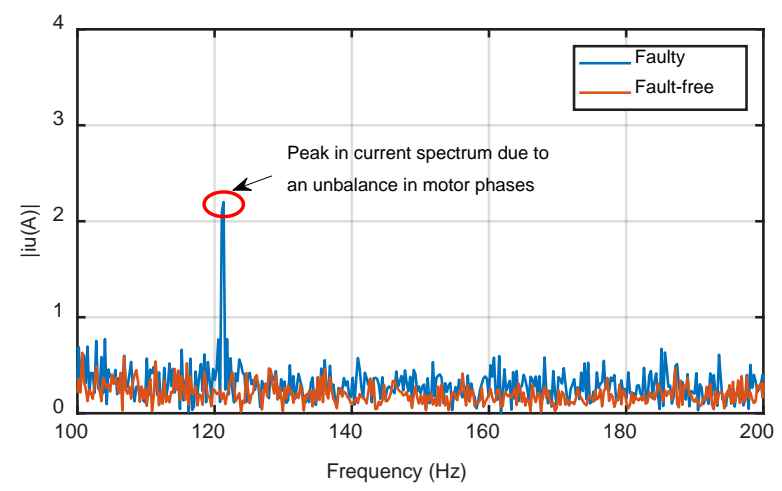

Figure 11. Comparison of stator current frequency spectrums for balanced and unbalanced motor phases.

\subsection{Fault Diagnosis in Sensors}

Several sensors are located in a Railway traction drive. A review is presented in [21]. Current and voltage sensors, such as catenary current, motor phase current and DC-link voltage, are based on Hall-Effect. In Hall-effect sensors, offset and gain faults can arise due to magnetic core degradation, magnetic properties variation with temperature or change of the magnetic field orientation [88]. Speed sensors in Railway applications are normally variable reluctance sensors, or Hall-Effect sensors. Commonly, sensors take part in the control strategy, so hard faults, such as sensor disconnection; have as consequence the protections activation. Thus, early diagnosis is not possible in these cases, although it can help for a faster corrective maintenance.

Among the sensor fault diagnosis articles in Railway traction drives, in [67] a Luenberger observer based approach for DC-link voltage and catenary current sensor fault diagnosis is presented The observer design is based on the rectifier model. A bank of residuals, taken from Luenberger observer errors and open loop estimations, are used for fault isolation. The FDI approach is validated in an experimental test bench. Similar to this, in [31] another approach is presented, using the input filter model for a DC supplied traction drive. In this case, the approach is validated in a Hardware-in-the-loop platform (HIL) with a commercial TCU for a tram. Furthermore, a fusion of different FDI approaches is proposed to improve the reliability of the fault isolation. A unknown input observer (UIO) is proposed in [68], using the inverter model instead of the rectifier model and in order to get a FTC. UIO is implemented due to the unknown inputs in the inverter model. A sliding mode observer (SMO) is proposed in [69], again with the rectifier model. Compared to Luenberger observer, SMO can be applied to non-linear systems and it has a better robustness under modelling uncertainties and measurement noises. In [70] a bank of SMO observers is proposed for DC-link voltage and catenary current sensors. Later, in [33] a SMO in combination with adaptive techniques in order to detect the different fault modes for a DC-link voltage sensor is presented. In [69] a SMO-based sensor FDI for incipient faults is presented. Adaptive thresholds are proposed in order to improve detectability. Finally, [71] presents the DC-link and catenary current sensors fault reconstruction based on a SMO and the equivalent injection signal. Equivalent injection signal represents the average value to maintain sliding motion. The application of equivalent injection signal requires the treatment of sensors as actuators, so a new augmented system should be designed from original system and sensors to be detected. The SMO for the augmented system is shown in Figure 12 , being $\mathbf{G}_{\mathbf{1}}$ and $\mathbf{G}_{\mathbf{n}}$ feedback matrix gains, whereas $v$ is the nonlinear term responsible for sliding motion. 


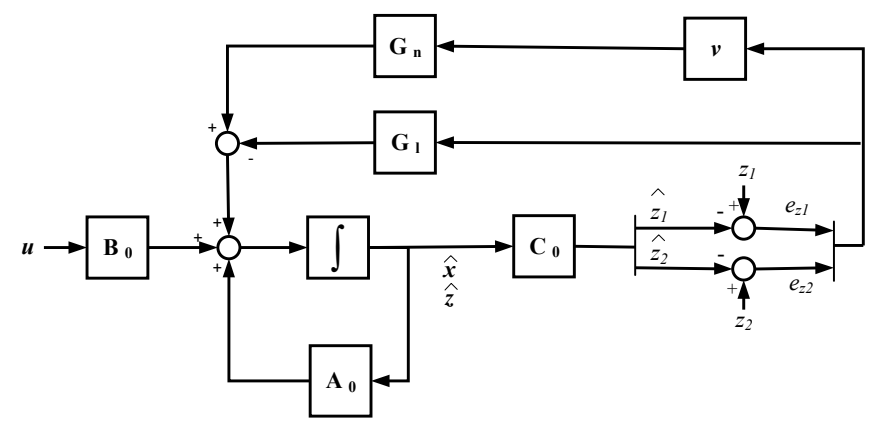

Figure 12. Sliding mode observer (SMO) proposed in [71] for sensor fault diagnosis.

Moreover, this approach is validated in a HIL platform too, composed of a Real Time simulator and a commercial TCU. The fault reconstruction for a gain fault injected in DC-link voltage sensor is shown in Figure 13.

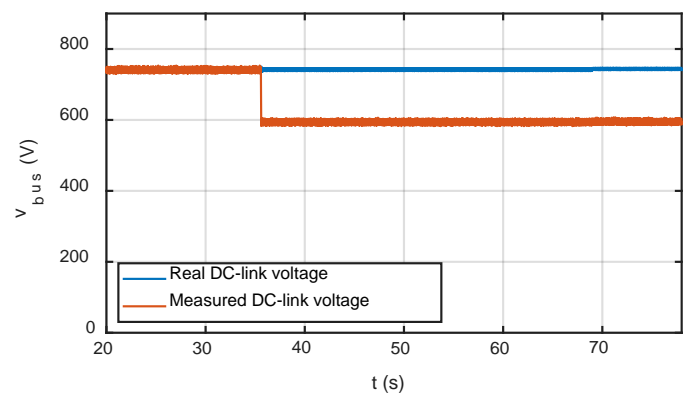

(a)

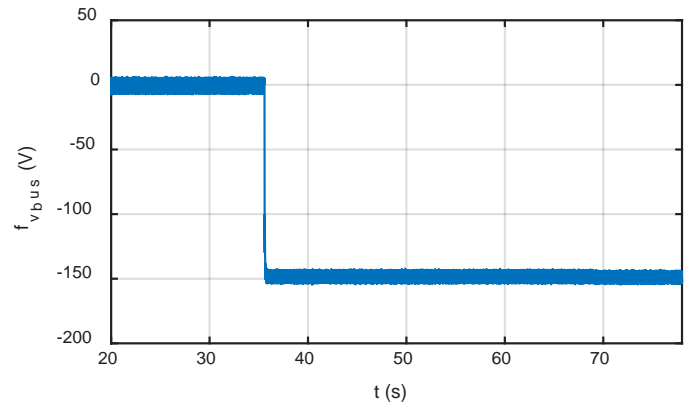

(b)

Figure 13. (a) Real and measured DC-link voltage; (b) DC-link voltage sensor fault reconstruction.

On the other hand, in [72] another approach is presented for a nonlinear system, presented as a Takagi-Sukeno Fuzzy model. This approach is based on the total measurable fault information residual (ToMFIR) for fault isolation, whereas a bank of observers is used for residuals generation. ToMFIR technique is presented in [73] too. This article affirms that the solution proposed can achieve a better solution for sensor fault detection than observer-based approaches, as well as a more general FDD framework. A HIL platform is used for validation, composed of a Real Time Simulator, an induction motor, a rectifier and a current sensor. Another data-driven approach is presented in [74], where Independent Component Analysis (ICA) in combination with Kullback-Leibler divergence (KLD) is presented to detect incipient faults in motor current sensors. ICA, in contrast to PCA, provides satisfactory results for non-Gaussian measurement signals. Furthermore, this approach does not require the probability density function (PDF) calculation, reducing the computational cost and allowing an online implementation. Recently, a new approach based on PCA and called probability relevant PCA [75], presents a comparison among different PCA-based approaches. It reduces the 
missing alarm ratio and false alarm rate in case of incipient faults in current and voltage sensors of an electrical drive for a high-speed train.

\subsection{Fault Diagnosis in Power Electronics}

The main power converters in Railway traction drives are the inverter to supply the electric machines and the braking chopper, as it is shown in Figure 14. Usually more than one electric machine is supplied with the same inverter. The goal of the chopper is to dissipate the energy during braking period that it is not possible to return to catenary. IGBT based power converters are mainly used for Railway traction drives [89]. A rectifier needs to be added in case of AC supplied traction units. The most usual faults in the power electronics of Railway traction drive occur in capacitor and power switches [90]. The main faults in IGBTs are given in [91]. DC-link capacitor main faults are summarized in [92].

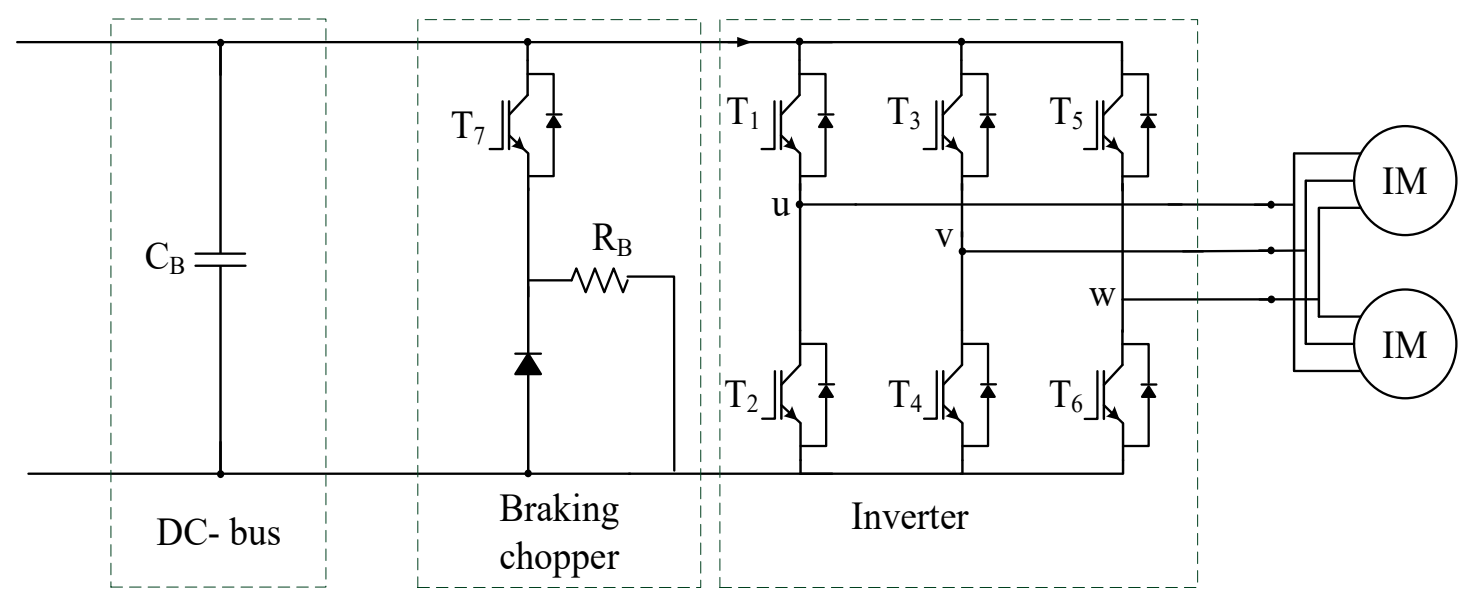

Figure 14. Power electronics for a traction drive connected to DC catenary.

In [32] a model-based estimator is proposed to detect faults in the switches of a single-phase PWM rectifier and later for cascaded H-bridge rectifiers [76]. The approach is validated in a HIL platform composed of a Real Time Simulator and a TCU. Only catenary current, DC-link voltage and switching signals from TCU are needed. Wavelet entropy approach is used in [77] to detect open switches in a inverter for High-Speed railways. The detection method is based on the hypothesis that the motor current for faulty case has more frequency components that for the fault-free case. In [78] a discrete wavelet transform is used and then the signal is decomposed into energy vectors. A support vector machine (SVM) is applied for IGBT faults classification. In [79] a signal-based approach is presented to detect open-circuit faults in IGBTs of rectifier. The detection is based of FFT analysis, due to the frequency harmonics change in case of faulty switch. The patterns detected in case of IGBT faults are presented in [80]. This research works affirms that a latch-up process generates an overcurrent whereas a secondary breakdown produces an overtemperature. In [81] a estimation of the capacitance of the DC-link capacitor is done during its discharge, by mean of least mean square algorithm. In this case, a real time fault diagnosis is not implement but it is justified that there are several train stops, so the calculation can be done.

\section{Discussion and Conclusions}

CBM is relatively new in Railway applications but an increasing importance in availability, as well as maintenance cost reduction, has made it a key point. The importance of traction drive in Railway system has led to develop fault diagnosis approaches for the Health Assessment of the traction drive. Although the literature is not so broad in Health Assessment in Railway traction drives, compared to aerospace systems, during the last decade a variety of research works have been done. 
Despite there are interesting reviews in Health assessment for on-board mechanical systems, such as wheel, suspension or bogie frame, there is a need to summarize all the research work carried out, both in fault diagnosis and health assessment, in Railway Traction drives, as part of a CBM framework.

The framework for CBM implementation is based on Standard ISO13374, initially developed for diagnosis of machines. As moving vehicle, different topologies are presented for CBM implementation, depending on the location Health Assessment module of Standard ISO13374. Thus, it is possible to implement a remote or on-board diagnosis. Furthermore, the diagnosis can be distributed or centralized. In case of remote diagnosis, a huge quantity of data should be transferred to off-board maintenance centre, due to variety of variables and high sample time, with the constraints of a moving vehicle, such as connectivity or data storage on-board. Then, fault diagnosis approaches, mainly data-driven, can be used for Health Assessment. It is not possible to implement a real-time fault detection but it can be a suitable solution for prognosis or for faults with low dynamics. In the near future, due to the advances in communications between on-board and remote systems, data would be transferred with a latency of $100 \mathrm{~ms}$, which could be enough to detect faults in systems with low dynamics. Nowadays, main rail equipment manufacturers provide supervision systems, which allow transferring data from on-board traction unit to remote maintenance centre, for a further analysis.

On the other hand, in case of on-board diagnosis, the fault detection can be in real-time and there is no need of huge quantity of data to be transferred to off-board maintenance centre, as Health Assessment is done on-board. A faster fault detection and isolation is done, allowing a further reconfiguration for a fault tolerant system. Model-based or signal-based approaches, which do not need to store huge quantity of data, could be suitable. As a possible drawback, the computational cost to implement the diagnosis algorithms in the on-board control traction unit.

Among the fault diagnosis approaches implemented for Railway traction drives, signal-based approaches are mainly used in electrical machines, in order to detect rotor bars breakage or eccentricities. Wavelet transform has been implemented to detect open-circuit faults in power switches. Wavelet transform is used in combination with classification techniques too.

Among the model-based approaches implemented for sensor fault detection, observer-based approaches are mainly utilized. Moreover, fault reconstruction by mean of a sliding mode observer is implemented too. Fusion of different model-based approaches are presented too in order to detect and isolate the faults in all the sensors located in a traction drive.

Finally, data-driven approaches PCA and ICA are used for sensor fault detection, applied to incipient fault detection. First, an offline stage for threshold setting is needed, based on historical fault-free data and finally the online detection is done by processing the actual data. The main drawback of these statistical analysis based approaches for on-board implementation could be the data storage capacity, until data can be transferred to remote maintenance centre and the high computational cost. Due to the fact that apart from score vectors calculation, normally PDF and statistics tests need to be calculated. On the other hand, it is not needed the knowledge of the physical system to build a model, as it is required in Model-based approaches. A combination of model-based and data-driven approaches can benefit from both methods, in order to detect and isolate faults with different dynamics.

Moreover, among the scientific publications, most of the fault diagnosis presented are implemented in lab platforms and only few of them implemented the diagnosis approaches in a Railway traction control unit, considering the computational limitations of the real Railway application. In this case, HIL platforms composed of a commercial Railway traction control unit and a real time simulator are used for validation.

Author Contributions: Conceptualization, F.G. and J.P.; Investigation, F.G., P.M. and J.d.O.; Writing-Original Draft Preparation, F.G. and J.P.; Writing-Review \& Editing, P.M., J.d.O. and G.A.

Funding: This research was supported by CAF Power and Automation.

Acknowledgments: The authors are thankful to the colleagues from CAF Power and Automation, who provided material and expertise that greatly assisted the research.

Conflicts of Interest: The authors declare no conflict of interest. 


\section{References}

1. Ahmad, R.; Kamaruddin, S. An overview of time-based and condition-based maintenance in industrial application. Comput. Ind. Eng. 2012, 63, 135-149. [CrossRef]

2. ISO. ISO 13374-1:2003 Condition Monitoring and Diagnostics of Machines_Data Processing, Communication and Presentation-Part 1: General Guidelines; ISO: Geneva, Switzerland, 2003.

3. Gouriveau, R.; Medjaher, K.; Zerhouni, N. From Prognostics and Health Systems Management to Predictive Maintenance 1; John Wiley \& Sons, Inc.: Hoboken, NJ, USA, 2016; ISBN 9781119371052.

4. Djeziri, M.A.; Benmoussa, S.; Sanchez, R. Hybrid method for remaining useful life prediction in wind turbine systems. Renew. Energy 2018, 116, 173-187. [CrossRef]

5. Yin, S.; Ding, S.X.; Xie, X.; Luo, H. A Review on Basic Data-Driven Approaches for Industrial Process Monitoring. IEEE Trans. Ind. Electron. 2014, 61, 6418-6428. [CrossRef]

6. Khorasgani, H.; Jung, D.; Biswas, G. Structural Approach for Distributed Fault Detection and Isolation. IFAC-PapersOnLine 2015, 48, 72-77. [CrossRef]

7. Gao, Z.; Cecati, C.; Ding, S.X. A Survey of Fault Diagnosis and Fault-Tolerant Techniques-Part I: Fault Diagnosis With Model-Based and Signal-Based Approaches. IEEE Trans. Ind. Electron. 2015, 62, 3757-3767. [CrossRef]

8. Ding, S. Model-Based Fault Diagnosis Techniques; Springer: Berlin/Heidelberg, Germany, 2008; ISBN 978-3-540-76303-1.

9. Tidriri, K.; Chatti, N.; Verron, S.; Tiplica, T. Bridging data-driven and model-based approaches for process fault diagnosis and health monitoring: A review of researches and future challenges. Annu. Rev. Control 2016, 42, 63-81. [CrossRef]

10. Hwang, I.; Kim, S.; Kim, Y.; Eng, C. A Survey of Fault Detection, Isolation, and Reconfiguration Methods. IEEE Trans. Control Syst. Technol. 2010, 18, 636-653. [CrossRef]

11. Wang, H.; Chai, T.-Y.; Ding, J.-L.; Brown, M. Data Driven Fault Diagnosis and Fault Tolerant Control: Some Advances and Possible New Directions. Acta Autom. Sin. 2009, 35, 739-747. [CrossRef]

12. Liu, R.; Yang, B.; Zio, E.; Chen, X. Artificial intelligence for fault diagnosis of rotating machinery: A review. Mech. Syst. Signal Process. 2018, 108, 33-47. [CrossRef]

13. Djeziri, M.A.; Bouamama, B.O.; Merzouki, R. Bond Graph Modelling of Engineering Systems; Borutzky, W., Ed.; Springer: New York, NY, USA, 2011; ISBN 978-1-4419-9367-0.

14. Triki-Lahiani, A.; Bennani-Ben Abdelghani, A.; Slama-Belkhodja, I. Fault detection and monitoring systems for photovoltaic installations: A review. Renew. Sustain. Energy Rev. 2018, 82, 2680-2692. [CrossRef]

15. Yang, Z.; Chai, Y. A survey of fault diagnosis for onshore grid-connected converter in wind energy conversion systems. Renew. Sustain. Energy Rev. 2016, 66, 345-359. [CrossRef]

16. Marzat, J.; Piet-Lahanier, H.; Damongeot, F.; Walter, E. Model-based fault diagnosis for aerospace systems: A survey. Proc. Inst. Mech. Eng. Part G J. Aerosp. Eng. 2012, 226, 1329-1360. [CrossRef]

17. Li, C.; Luo, S.; Cole, C.; Spiryagin, M. An overview: Modern techniques for railway vehicle on-board health monitoring systems. Veh. Syst. Dyn. 2017, 55, 1045-1070. [CrossRef]

18. Feng, D.; Lin, S.; He, Z.; Sun, X. A technical framework of PHM and active maintenance for modern high-speed railway traction power supply systems. Int. J. Rail Transp. 2017, 5, 145-169. [CrossRef]

19. Kia, S.H.; Henao, H.; Capolino, G.-A. Mechanical health assessment of a railway traction system. In Proceedings of the MELECON 2008-The 14th IEEE Mediterranean Electrotechnical Conference, Ajaccio, France, 5-8 May 2008; pp. 453-458.

20. Sa, J.; Choi, Y.; Chung, Y.; Kim, H.-Y.; Park, D.; Yoon, S. Replacement Condition Detection of Railway Point Machines Using an Electric Current Sensor. Sensors 2017, 17, 263. [CrossRef]

21. Feng, J.; Xu, J.; Liao, W.; Liu, Y. Review on the Traction System Sensor Technology of a Rail Transit Train. Sensors 2017, 17, 1356. [CrossRef]

22. Yu, X.; Jiang, J. A survey of fault-tolerant controllers based on safety-related issues. Annu. Rev. Control 2015, 39, 46-57. [CrossRef]

23. Capolino, G.-A.; Antonino-Daviu, J.A.; Riera-Guasp, M. Modern Diagnostics Techniques for Electrical Machines, Power Electronics, and Drives. IEEE Trans. Ind. Electron. 2015, 62, 1738-1745. [CrossRef]

24. Yu, Y.; Zhao, Y.; Wang, B.; Huang, X.; Xu, D.G. Current Sensor Fault Diagnosis and Tolerant Control for VSI-Based Induction Motor Drives. IEEE Trans. Power Electron. 2017, PP , 1. [CrossRef] 
25. Najafabadi, T.A.; Salmasi, F.R.; Jabehdar-Maralani, P. Detection and isolation of speed-, DC-link voltage-, and current-sensor faults based on an adaptive observer in induction-motor drives. IEEE Trans. Ind. Electron. 2011, 58, 1662-1672. [CrossRef]

26. Bourogaoui, M.; Sethom, H.B.A.; Belkhodja, I.S. Speed/position sensor fault tolerant control in adjustable speed drives-A review. ISA Trans. 2016, 64, 269-284. [CrossRef] [PubMed]

27. Poon, J.; Jain, P.; Konstantakopoulos, I.C.; Spanos, C.; Panda, S.K.; Sanders, S.R. Model-Based Fault Detection and Identification for Switching Power Converters. IEEE Trans. Power Electron. 2017, 32, 1419-1430. [CrossRef]

28. Merizalde, Y.; Hernández-Callejo, L.; Duque-Perez, O. State of the Art and Trends in the Monitoring, Detection and Diagnosis of Failures in Electric Induction Motors. Energies 2017, 10, 1056. [CrossRef]

29. Liu, Y.; Bazzi, A.M. A review and comparison of fault detection and diagnosis methods for squirrel-cage induction motors: State of the art. ISA Trans. 2017, 70, 400-409. [CrossRef]

30. Riera-Guasp, M.; Antonino-Daviu, J.A.; Capolino, G.-A. Advances in Electrical Machine, Power Electronic, and Drive Condition Monitoring and Fault Detection: State of the Art. IEEE Trans. Ind. Electron. 2015, 62, 1746-1759. [CrossRef]

31. Garramiola, F.; del Olmo, J.; Poza, J.; Madina, P.; Almandoz, G. Integral Sensor Fault Detection and Isolation for Railway Traction Drive. Sensors 2018, 18, 1543. [CrossRef] [PubMed]

32. Gou, B.; Ge, X.; Wang, S.; Feng, X.; Kuo, J.B.; Habetler, T.G. An Open-Switch Fault Diagnosis Method for Single-Phase PWM Rectifier Using a Model-Based Approach in High-Speed Railway Electrical Traction Drive System. IEEE Trans. Power Electron. 2016, 31, 3816-3826. [CrossRef]

33. Zhang, K.; Jiang, B.; Yan, X.-G.; Mao, Z. Incipient Voltage Sensor Fault Isolation for Rectifier in Railway Electrical Traction Systems. IEEE Trans. Ind. Electron. 2017, PP, 1. [CrossRef]

34. Jardine, A.K.S.; Lin, D.; Banjevic, D. A review on machinery diagnostics and prognostics implementing condition-based maintenance. Mech. Syst. Signal Process. 2006, 20, 1483-1510. [CrossRef]

35. Alaswad, S.; Xiang, Y. A review on condition-based maintenance optimization models for stochastically deteriorating system. Reliab. Eng. Syst. Saf. 2017, 157, 54-63. [CrossRef]

36. Olde Keizer, M.C.A.; Flapper, S.D.P.; Teunter, R.H. Condition-based maintenance policies for systems with multiple dependent components: A review. Eur. J. Oper. Res. 2017, 261, 405-420. [CrossRef]

37. Shin, J.-H.; Jun, H.-B. On condition based maintenance policy. J. Comput. Des. Eng. 2015, 2, 119-127. [CrossRef]

38. de Jonge, B.; Teunter, R.; Tinga, T. The influence of practical factors on the benefits of condition-based maintenance over time-based maintenance. Reliab. Eng. Syst. Saf. 2017, 158, 21-30. [CrossRef]

39. Guillén, A.J.; Crespo, A.; Gómez, J.F.; Sanz, M.D. A framework for effective management of condition based maintenance programs in the context of industrial development of E-Maintenance strategies. Comput. Ind. 2016, 82, 170-185. [CrossRef]

40. Del Olmo, J.; Poza, J.; Garramiola, F.; Nieva, T.; Aldasoro, L. Model driven Hardware-in-the-Loop Fault analysis of railway traction systems. In Proceedings of the 2017 IEEE International Workshop of Electronics, Control, Measurement, Signals and their Application to Mechatronics (ECMSM), San Sebastian, Spain, 24-26 May 2017; pp. 1-6.

41. Le Mortellec, A. Proposition d'une Architecture de Surveillance "Active" à base d'agents Intelligents Pour l'aide à la Maintenance de Systèmes Mobiles Application au Domaine Ferroviaire; Université de Valenciennes et du Hainaut-Cambresis: Famars, France, 2014.

42. Ai, B.; Guan, K.; Rupp, M.; Kurner, T.; Cheng, X.; Yin, X.-F.; Wang, Q.; Ma, G.-Y.; Li, Y.; Xiong, L.; et al. Future railway services-oriented mobile communications network. IEEE Commun. Mag. 2015, 53, 78-85. [CrossRef]

43. Jiang, X.; Li, G. Research on Fault Prognostics and Health Management of the on-Board Equipment of CTCS-3 Train Control System. Int. J. Secur. Appl. 2016, 10, 175-186. [CrossRef]

44. Ciocoiu, L.; Siemieniuch, C.E.; Hubbard, E.-M. From preventative to predictive maintenance: The organisational challenge. Proc. Inst. Mech. Eng. Part F J. Rail Rapid Transit 2017, 231, 1174-1185. [CrossRef]

45. Yokoyama, A. Innovative Changes for Maintenance of Railway by Using ICT-To Achieve "Smart Maintenance". Procedia CIRP 2015, 38, 24-29. [CrossRef]

46. Shift2Rail. Available online: https://shift2rail.org/ (accessed on 29 November 2018).

47. Yang, C.; Yang, C.; Peng, T.; Yang, X.; Weihua, G. A Fault-Injection Strategy for Traction Drive Control Systems. IEEE Trans. Ind. Electron. 2017, PP, 1. [CrossRef] 
48. del Olmo, J.; Garramiola, F.; Poza, J.; Almandoz, G. Model-Based Fault Analysis for Railway Traction Systems. In Modern Railway Engineering; Hessami, A., Ed.; InTech: Rijeka, Croatia, 2018; ISBN 978-953-51-3860-0.

49. Yang, X.; Yang, C.; Peng, T.; Chen, Z.; Liu, B.; Gui, W. Hardware-in-the-Loop Fault Injection for Traction Control System. IEEE J. Emerg. Sel. Top. Power Electron. 2018, 6, 696-706. [CrossRef]

50. Fraga-Lamas, P.; Fernández-Caramés, T.M.; Castedo, L. Towards the Internet of Smart Trains: A Review on Industrial IoT-Connected Railways. Sensors 2017, 17, 1457. [CrossRef] [PubMed]

51. Atamuradov, V.; Medjaher, K.; Dersin, P.; Lamoureux, B.; Zerhouni, N. Prognostics and Health Management for Maintenance Practitioners -Review, Implementation and Tools Evaluation. Int. J. Progn. Heal. Manag. 2017, 2153-2648.

52. Karakose, M.; Yaman, O.; Murat, K.; Akin, E. A New Approach for Condition Monitoring and Detection of Rail Components and Rail Track in Railway. Int. J. Comput. Intell. Syst. 2018, 11, 830-845. [CrossRef]

53. Wu, Y.; Qin, Y.; Wang, Z.; Jia, L. A UAV-Based Visual Inspection Method for Rail Surface Defects. Appl. Sci. 2018, 8, 1028. [CrossRef]

54. Wei, J.; Liu, C.; Ren, T.; Liu, H.; Zhou, W. Online Condition Monitoring of a Rail Fastening System on High-Speed Railways Based on Wavelet Packet Analysis. Sensors 2017, 17, 318. [CrossRef] [PubMed]

55. Gao, R.X.; Yan, R. Wavelets; Springer: Boston, MA, USA, 2011; ISBN 978-1-4419-1544-3.

56. Gómez, M.; Corral, E.; Castejón, C.; García-Prada, J. Effective Crack Detection in Railway Axles Using Vibration Signals and WPT Energy. Sensors 2018, 18, 1603. [CrossRef]

57. Cheng, Y.; Zhou, N.; Zhang, W.; Wang, Z. Application of an improved minimum entropy deconvolution method for railway rolling element bearing fault diagnosis. J. Sound Vib. 2018, 425, 53-69. [CrossRef]

58. Espinosa, F.; García, J.J.; Hernández, A.; Mazo, M.; Ureña, J.; Jiménez, J.A.; Fernández, I.; Pérez, C.; García, J.C. Advanced monitoring of rail breakage in double-track railway lines by means of PCA techniques. Appl. Soft Comput. 2018, 63, 1-13. [CrossRef]

59. Chen, Z. Data-Driven Fault Detection for Industrial Processes; Springer: Wiesbaden, Germany, 2017; ISBN 978-3-658-16755-4.

60. Dai, C.; Huang, K.; Hu, K.; Liu, Z. Fault diagnosis approach of traction transformers in high-speed railway combining kernel principal component analysis with random forest. IET Electr. Syst. Transp. 2016, 6, $202-206$. [CrossRef]

61. Liu, Z.; Hu, K. A Model-Based Diagnosis System for a Traction Power Supply System. IEEE Trans. Ind. Inform. 2017, 13, 2834-2843. [CrossRef]

62. Mao, Z.; Zhan, Y.; Tao, G.; Jiang, B.; Yan, X.-G. Sensor Fault Detection for Rail Vehicle Suspension Systems With Disturbances and Stochastic Noises. IEEE Trans. Veh. Technol. 2017, 66, 4691-4705. [CrossRef]

63. Bruzzese, C.; Honorati, O.; Santini, E. Rotor bars breakage in railway traction squirrel cage induction motors and diagnosis by MCSA technique Part I: Accurate fault simulations and spectral analyses. In Proceedings of the 2005 5th IEEE International Symposium on Diagnostics for Electric Machines, Power Electronics and Drives, Vienna, Austria, 7-9 September 2005; pp. 1-6.

64. Cruz, S.M.A.; Stefani, A.; Filippetti, F.; Cardoso, A.J.M. A New Model-Based Technique for the Diagnosis of Rotor Faults in RFOC Induction Motor Drives. IEEE Trans. Ind. Electron. 2008, 55, 4218-4228. [CrossRef]

65. Sancho, C.; Gomez-Parra, M.; Munoz-Condes, P.; San Andres, M.A.G.; Gonzalez-Fernandez, F.J.; Carpio, J.; Guirado, R. Advanced Maintenance of Rail Traction Motors Using a Magnetic Leakage Flux Technique. IEEE Trans. Ind. Appl. 2012, 48, 942-951. [CrossRef]

66. Zoeller, C.; Vogelsberger, M.A.; Fasching, R.; Grubelnik, W.; Wolbank, T.M. Evaluation and Current-Response-Based Identification of Insulation Degradation for High Utilized Electrical Machines in Railway Application. IEEE Trans. Ind. Appl. 2017, 53, 2679-2689. [CrossRef]

67. Youssef, A.B.; El Khil, S.K.; Slama-Belkhodja, I. State Observer-Based Sensor Fault Detection and Isolation, and Fault Tolerant Control of a Single-Phase PWM Rectifier for Electric Railway Traction. IEEE Trans. Power Electron. 2013, 28, 5842-5853. [CrossRef]

68. Zhang, K.; Jiang, B.; Yan, X.-G.; Mao, Z. Incipient sensor fault estimation and accommodation for inverter devices in electric railway traction systems. Int. J. Adapt. Control Signal Process. 2017, 31, 785-804. [CrossRef]

69. Zhang, K.; Jiang, B.; Yan, X.-G.; Mao, Z. Sliding mode observer based incipient sensor fault detection with application to high-speed railway traction device. ISA Trans. 2016, 63, 49-59. [CrossRef]

70. Xia, J.; Guo, Y.; Dai, B.; Zhang, X. Sensor Fault Diagnosis and System Reconfiguration Approach for Electric Traction PWM Rectifier Based on Sliding Mode Observer. IEEE Trans. Ind. Appl. 2017, PP, 1. [CrossRef] 
71. Garramiola, F.; Poza, J.; del Olmo, J.; Madina, P.; Almandoz, G. DC-Link Voltage and Catenary Current Sensors Fault Reconstruction for Railway Traction Drives. Sensors 2018, 18, 1998. [CrossRef]

72. Wu, Y.; Jiang, B.; Shi, P. Incipient fault diagnosis for T-S fuzzy systems with application to high-speed railway traction devices. IET Control Theory Appl. 2016, 10, 2286-2297. [CrossRef]

73. Wu, Y.; Jiang, B.; Lu, N.; Yang, H.; Zhou, Y. Multiple incipient sensor faults diagnosis with application to high-speed railway traction devices. ISA Trans. 2017, 67, 183-192. [CrossRef]

74. Chen, H.; Jiang, B.; Lu, N.; Chen, W. Real-time incipient fault detection for electrical traction systems of CRH2. Neurocomputing 2018, 306, 119-129. [CrossRef]

75. Chen, H.; Jiang, B.; Chen, W.; Yi, H. Data-driven Detection and Diagnosis of Incipient Faults in Electrical Drives of High-Speed Trains. IEEE Trans. Ind. Electron. 2018, 1. [CrossRef]

76. Xie, D.; Ge, X. Open-circuit fault diagnosis for single-phase cascaded H-bridge rectifiers in electrical traction systems. In Proceedings of the 2017 IEEE Transportation Electrification Conference and Expo, Asia-Pacific (ITEC Asia-Pacific), Harbin, China, 7-10 August 2017; pp. 1-6.

77. Hu, K.; Liu, Z.; Lin, S. Wavelet Entropy-Based Traction Inverter Open Switch Fault Diagnosis in High-Speed Railways. Entropy 2016, 18, 78. [CrossRef]

78. Fei, M.; Ning, L.; Huiyu, M.; Yi, P.; Haoyuan, S.; Jianyong, Z. On-line fault diagnosis model for locomotive traction inverter based on wavelet transform and support vector machine. Microelectron. Reliab. 2018, 88-90, 1274-1280. [CrossRef]

79. Tian, Z.; Ge, X. An on-line fault diagnostic method based on frequency-domain analysis for IGBTs in traction PWM rectifiers. In Proceedings of the 2016 IEEE 8th International Power Electronics and Motion Control Conference (IPEMC-ECCE Asia), Hefei, China, 22-26 May 2016; pp. 3403-3407.

80. Perpiñà, X.; Serviere, J.F.; Jordà, X.; Fauquet, A.; Hidalgo, S.; Urresti-Ibañez, J.; Rebollo, J.; Mermet-Guyennet, M. IGBT module failure analysis in railway applications. Microelectron. Reliab. 2008, 48, 1427-1431. [CrossRef]

81. Buiatti, G.M.; Martin-Ramos, J.A.; Amaral, A.M.R.; Dworakowski, P.; Cardoso, A. Condition Monitoring of Metallized Polypropylene Film Capacitors in Railway Power Trains. IEEE Trans. Instrum. Meas. 2009, 58, 3796-3805. [CrossRef]

82. Torrent, M.; Perat, J.; Jiménez, J. Permanent Magnet Synchronous Motor with Different Rotor Structures for Traction Motor in High Speed Trains. Energies 2018, 11, 1549. [CrossRef]

83. Bonnett, A.; Yung, C. Increased Efficiency Versus Increased Reliability. IEEE Ind. Appl. Mag. 2008, 14, 29-36. [CrossRef]

84. Bellini, A.; Filippetti, F.; Tassoni, C.; Capolino, G.-A. Advances in Diagnostic Techniques for Induction Machines. IEEE Trans. Ind. Electron. 2008, 55, 4109-4126. [CrossRef]

85. Glowacz, A.; Glowacz, Z. Diagnosis of the three-phase induction motor using thermal imaging. Infrared Phys. Technol. 2017, 81, 7-16. [CrossRef]

86. Maraaba, L.; Al-Hamouz, Z.; Abido, M. An Efficient Stator Inter-Turn Fault Diagnosis Tool for Induction Motors. Energies 2018, 11, 653. [CrossRef]

87. Morinigo-Sotelo, D.; Romero-Troncoso, R.D.J.; Panagiotou, P.A.; Antonino-Daviu, J.A.; Gyftakis, K.N. Reliable Detection of Rotor Bars Breakage in Induction Motors via MUSIC and ZSC. IEEE Trans. Ind. Appl. 2018, 54, 1224-1234. [CrossRef]

88. Balaban, E.; Saxena, A.; Bansal, P.; Goebel, K.F.; Curran, S. Modeling, Detection, and Disambiguation of Sensor Faults for Aerospace Applications. IEEE Sens. J. 2009, 9, 1907-1917. [CrossRef]

89. Ronanki, D.; Singh, S.A.; Williamson, S.S. Comprehensive Topological Overview of Rolling Stock Architectures and Recent Trends in Electric Railway Traction Systems. IEEE Trans. Transp. Electrif. 2017, 3, 724-738. [CrossRef]

90. Fusco, L.; Pagano, M. An approach to design a prognostic based maintenance strategy for railway power converter unit. In Proceedings of the 2015 International Conference on Electrical Systems for Aircraft, Railway, Ship Propulsion and Road Vehicles (ESARS), Aachen, Germany, 3-5 March 2015; Volume 2015, pp. 1-6. 
91. Choi, U.M.; Blaabjerg, F.; Lee, K.B. Study and Handling Methods of Power IGBT Module Failures in Power Electronic Converter Systems. IEEE Trans. Power Electron. 2015, 30, 2517-2533. [CrossRef]

92. Wang, H.; Blaabjerg, F. Reliability of Capacitors for DC-Link Applications in Power Electronic Converters-An Overview. IEEE Trans. Ind. Appl. 2014, 50, 3569-3578. [CrossRef] 